\title{
Attrition of an aluminate-based synthetic sorbent for regenerative sulphur capture from flue gas in a fluidised bed
}

\author{
E.H.P. Wolff*, A.W. Gerritsen and P.J.T. Verheijen** \\ Department of Chemical Engineering, Delft University of Technology, P.O. Box 5045, 2600 GA Delft (Netherlands)
}

(Received July 14, 1992; in revised form March 12, 1993)

\begin{abstract}
Attrition tests have been performed on an aluminate-based synthetic sorbent intended for regenerative sulphur capture from flue gas in a fluidised bed coal combustor. A comparison with lime(stone) has also been made. Single-particle crushing strength tests have been used to investigate the role of breakage caused by static mechanical stress, while impact tests have been applied to study kinetic stress. Multi-particle fluidised bed tcsts have been used to examine attrition by thermal shock (thermal stress), coal combustion (thermal and chemical stress) and fluidisation (kinetic stress) independently. The attrition resistance of the synthetic sorbent is much higher than that of lime(stone). It appears however that the effect of coal combustion on sorbent attrition needs further research. The morphology of the sorbents is only slightly affected by the various tests mentioned above.
\end{abstract}

\section{Introduction}

The capture of sulphur oxides - mainly $\mathrm{SO}_{2}-$ from flue gas is a topic of current interest for environmental aspects. The most obvious route for this process is to 'absorb' the $\mathrm{SO}_{2}$ on, e.g., lime(stone) and subsequently dispose of the gypsum formed. However, this simple procedure wastes natural resources, viz. limestone, and does not draw on the potential use of the absorbed sulphur. An alternative to this process route is to use a sorbent, that can be regenerated and by which the sulphur is recovered.

An aluminate-based synthetic sorbent intended for regenerative sulphur capture from flue gas in a fluidised bed coal combustor was developed recently $[1,2,3]$. This sorbent (called SG105, which is characterized in Table 1) consists of $8.2 \mathrm{wt}$. $\% \mathrm{CaO}$ on a $\gamma-\mathrm{Al}_{2} \mathrm{O}_{3}$ support. It is prepared by the sol-gel method $[4,5]$. During the calcination step, calcium aluminates are formed. The synthetic sorbent can withstand temperatures up to 850 ${ }^{\circ} \mathrm{C}$. After sulphation at this temperature the sorbent can be regenerated also at $850^{\circ} \mathrm{C}$ with a reducing gas to produce a relatively concentrated $\mathrm{SO}_{2}$-gas.

A process scheme in which the synthetic sorbent is fed into a fluidised bed combustor for burning coal is given in Fig. 1 [6,7]. The sulphur-loaded sorbent accumulates in the bed and is transported with the

*Present address: Koninklijke/Shell-Laboratories, Amsterdam, P.O. Box 3003, 1003 AA, Amsterdam, Netherlands.

**Author to whom correspondence should be addressed. bottom coal ashes to another fluidised bed for ash separation and sorbent regeneration. The regenerated sorbent is recycled, the ashes are disposed of, and the concentrated $\mathrm{SO}_{2}$-gas is carried to another plant for further processing. This regenerative process is not yet economical $[4,6,7]$, but it is a promising long term option for cleaning flue gas.

An important consideration in this regenerative process is the attrition of the sorbent particles as it affects the process operability, e.g. fluidisation dynamics and loss of bed material. The control of fines generation needs to be considered to minimize downstream deposits and erosion. Environmental regulations, e.g. minimization of fine particle emission, cause additional process costs. Moreover, a change in sorbent diameter may influence the sulphur absorption process.

Vaux and Keairns [8] distinguish four mechanisms of attrition in fluidised beds: static mechanical stress, kinetic stress, thermal stress, and chemical stress. All these mechanisms take place simultaneously in fluidised bed coal combustors. Furthermore, the pneumatic conveying system envisaged in the above process may also contribute significantly to the total attrition.

The aim of this work is to estimate from laboratoryscale single-particle and multi-particle experiments the rate of sorbent attrition. The attrition behaviour of the synthetic sorbent SG105 is compared with that of limestone and lime (calcined limestone). The results can be used to enhance our understanding about attrition. Future work on attrition will finally determine its effects 
TABLE 1. Characterization of the limestone, lime and synthetic sorbent samples used in the experiments

\begin{tabular}{llllll}
\hline & Limestone & Lime & SG105 & SG110 & SG105 \\
\hline Shape & irregular & irregular & spherical & spherical & spherical \\
Diameter (mm) & $1.7-2.0$ & $1.7-2.0$ & $2.8-3.4$ & $2.8-3.4$ & $2.8-3.4$ \\
Ca-content (wt.\%) & 38.5 & 65.4 & 5.83 & 6.2 & $\sim 6$ \\
Major non-Ca component & $\mathrm{CO}_{3}{ }^{2-}$ & $\mathrm{CO}_{3}{ }^{2-}$ & $\gamma-\mathrm{Al}_{2} \mathrm{O}_{3}$ & $\mathrm{Al}_{2} \mathrm{O}_{3}$ & \multicolumn{2}{c}{$\mathrm{Al}_{2} \mathrm{O}_{3}$} \\
Particle density $\left(\mathrm{kg} \mathrm{m}^{-3}\right)$ & 2652 & 1609 & 1678 & $\sim 1700$ \\
\hline
\end{tabular}

"The lime was made by heating the limestone from room temperature to $850^{\circ} \mathrm{C}$ in air. The calcination step is subsequently carried out at a temperature of $850{ }^{\circ} \mathrm{C}$ for $10 \mathrm{~h}$.

'Sample previously used in a ten-cycle sulphation-regeneration experiment [6].

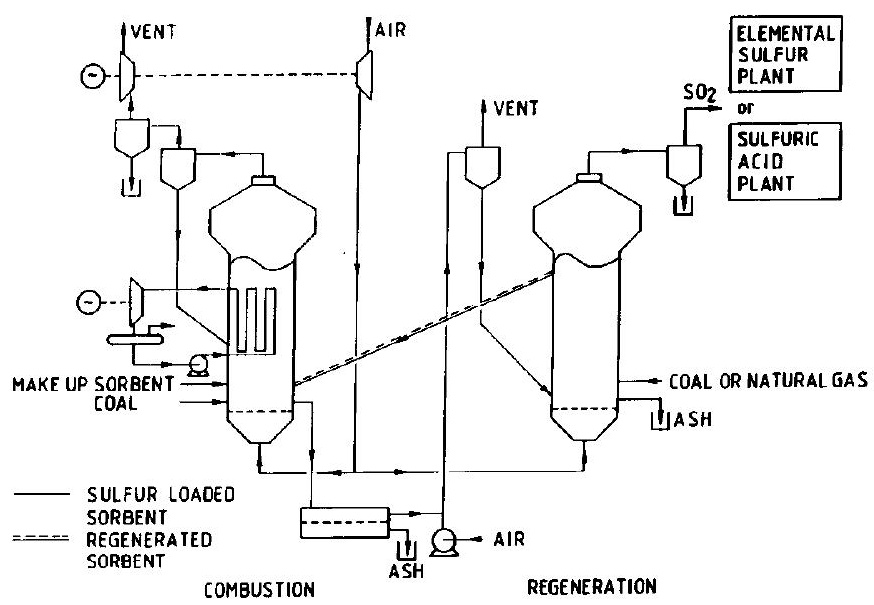

Fig. 1. Schematic flowscheme of fluidised bed coal combustion with regenerative desulphurisation.

on an industrial-scale regenerative desulphurisation process.

Several attrition tests are available (see, e.g., Bemrose and Bridgwater [9]) to measure the attrition tendency of fluidisable solids. Many of these tests assign a number to the rate of attrition based on a practical engineering measure. For example, the percentage of particles reduced to less than a certain size in a specified time within a specified test apparatus may be used as an index describing the attrition propensity of the particulate solids. Such an approach, which will also be used here, is only useful for quality and process control.

\section{Single-particle tests}

A single-particle crushing strength test is useful for investigating the role of breakage caused by static mechanical stress. The first test described in this section (the so-called 'Brazilian test') was performed with a Schleuniger-2E/205 instrument (Dr. K. Schleuniger \& $\mathrm{Co}$, Switzerland). A sorbent particle is placed between two smooth and parallel compression surfaces made of steel. One of the surfaces moves horizontally and the force is increased at a uniform rate of $44 \mathrm{~N} \mathrm{~s}^{-1}$ [10]. At the end of the test, the particle crushes or collapses and a pointer indicates the crushing force applied. Each test sample contained 100 separate particles randomly chosen from the bulk. The tests were performed using limestone (Belgian Carmeuse Engis), lime and fresh SG105. In addition, an SG105 sample, previously treated in a 10-cycle sulphation-regeneration fixed bed experiment, was tested. The sorbents are characterized in Table 1.

From the results listed in Table 2 , it is concluded that the crushing strength of the synthetic sorbent is significantly higher than that of (calcined) limestone, which makes the SG105 sorbent, qualitatively speaking, more suitable for regenerative fluidised bed operation. A comparison of the synthetic sorbent recycled ten times with fresh sorbent shows that no significant change in the crushing strength is measured. The strength of the SG105 sorbent is therefore unaffected by chemical stress during the 10 cycles of sulphur capture and regeneration processing. If the diameters of the particles are taken into account, the result is that limestone, SG105 and recycled SG105 are approximately equally strong while lime is still much weaker. It should, however, be noted here that the strength of limestone is of relatively little interest. Limestone is only fed to the process as make-up sorbent, while the bulk of the circulating solids is lime or recycled SG105.

The effect of kinetic stress, which may cause major attrition during transport in pneumatic conveying systems, was investigated by shooting sorbent particles on a rigid surface. Vervoorn et al. [11] have described the apparatus used for these experiments. It is in fact a

TABLE 2. Crushing strength [10] (average and sample standard deviation of a sample containing 100 particles)

\begin{tabular}{ll}
\hline Sample & $\begin{array}{l}\text { Crushing } \\
\text { strength }(N)\end{array}$ \\
\hline Limestone & $57 \pm 24$ \\
Lime & $<10$ \\
SG105 & $91 \pm 47$ \\
SG105 after ten & $89 \pm 50$ \\
sulphation-regeneration & \\
cycles in a fixed bed [6] & \\
\hline
\end{tabular}


gas gun and a flat-faced steel plane placed in a catcher tank. The particles are propelled with velocities in the range of 7-21 $\mathrm{m} \mathrm{s}^{-1}$, representative of particle velocities in pneumatic conveyors. The particles were directed at right angles to the plate. At each velocity fifty shots are fired. It was visually observed whether or not a particle broke at the impact. The shooting test was only performed with fresh SG105 sorbent, as lime is already partly pulverized by the act of shooting.

Figure 2 shows the dependence of breakage probability on impact velocity and a log-normal cumulative distribution (see appendix) fitted to these data. The scatter in the experiments at each impact velocity is as expected from a process with as a result 'success' or 'failure', namely a binomial distribution. The smooth transition from $2 \mathrm{~m} \mathrm{~s}^{-1}$, where a negligible amount of particles break, to $30 \mathrm{~m} \mathrm{~s}^{-1}$, where almost all particles break, is due to the stochastic nature of the physical processes determining the break-up: distributions of the mass of the particle, angle and force of impact, roughness of particle surface (crushing) strength of the particle, and the existence of surface flaws or cracks are all contributing factors [12]. A simple approximation relates the impact velocity at break-up to a break-up threshold force and the particle mass by:

$V_{\mathrm{t}} \propto \frac{F_{\mathrm{t}}}{m}$

from which it follows that the geometric standard deviations (the standard deviation of the variable on a logarithmic scale) are related by:

$\left(\ln \sigma_{\mathrm{V}_{\mathrm{L}}}\right)^{2}=\left(\ln \sigma_{\mathrm{F}}\right)^{2}+\left(\ln \sigma_{\mathrm{m}}\right)^{2}$

The geometric standard deviation of the SG105 crushing strength data ' $\ln \sigma_{\mathrm{F}_{\mathrm{t}}}=0.49$ ', derived from Table 2, as-

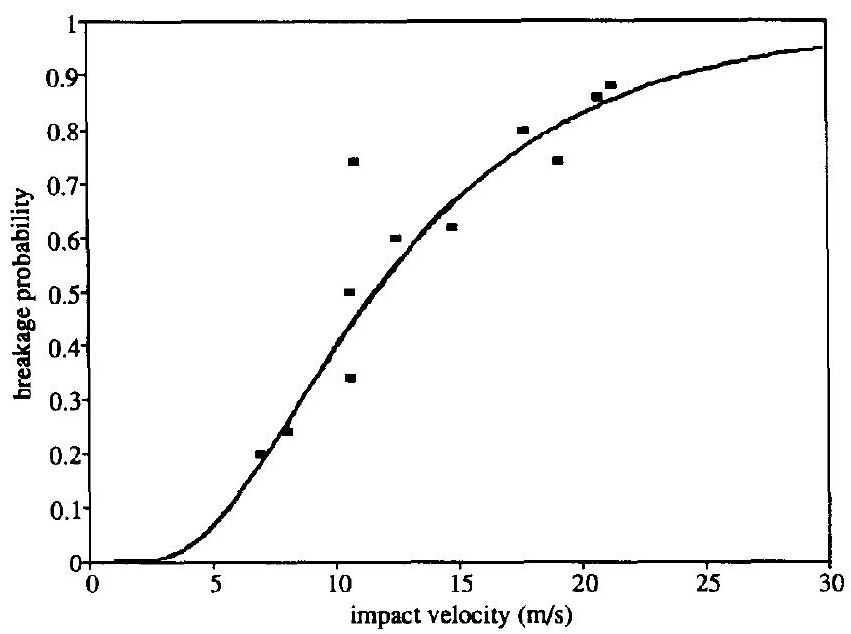

Fig. 2. Breakage fraction of SG105 sorbent as a function of impact velocity. The line drawn is that of a cumulative log-normal distribution fitted to the data points. The geometric average and standard deviation are respectively $11.7 \mathrm{~m} \mathrm{~s}^{-1}$ and 0.57 . suming that the distribution of the strength follows a log-normal distribution, is an estimate for the scatter in the break-up threshold force. This explains the value of the geometric standard deviation of the impact velocity at break-up: $\ln \sigma_{v_{t}}=0.57 \pm 0.05$ (Fig. 2). The difference can be explained with the help of eqn. (2) by inclusion of the range of the mass of the particles used: $\ln \sigma_{\mathrm{m}}=0.16$. The determining factor for the scatter in the impact velocity at break-up is therefore assumed to be the scatter in the break-up force.

\section{Fluidised bed tests}

Widely reported attrition tests use fluidised beds [9]. However, there is still no universal procedure to assess attrition for high-temperature operations with reactive particles in fluidised beds, because of the many attrition mechanisms involved. Separate investigations are necessary to determine which attrition mechanism dominates. Literature on attrition caused by thermal and chemical stress is sparse [13]. In order to determine the dominant attrition mechanism in reactive gas-solid systems, such as $\mathrm{CaO} / \gamma-\mathrm{Al}_{2} \mathrm{O}_{3} / \mathrm{SO}_{2} / \mathrm{O}_{2} / \mathrm{SO}_{3} /$ coal in the present work, experiments have been performed to estimate thermal, chemical and kinetic attrition rates independently. When fresh (make-up) sorbent is fed to the reactor, its temperature increases from room temperature to the average bed temperature $\left(850^{\circ} \mathrm{C}\right)$ in a relatively short period of time (calculations show in less than $10 \mathrm{~s}$ ). The sorbent is thus exposed to thermal stress. Moreover, the combustion of coal causes local hot-spots in the bed of up to $300^{\circ} \mathrm{C}$ higher than the average bed temperature of $850^{\circ} \mathrm{C}$ (possible source of thermal stress). Furthermore, the sulphur dioxide released from the coal is captured by the sorbent, resulting in a structural volume change. This may cause chemical stress within the particle.

Batch experiments were carried out in a $0.05 \mathrm{~m}$ ID atmospheric pressure fluidised bed. This facility simulates the (slugging) bed between the vertical heat exchanger tubes in a fluidised bed system. The reactor tube is made of quartz and is $1.2 \mathrm{~m}$ high. The lower section, $0.5 \mathrm{long}$, is heated to $850{ }^{\circ} \mathrm{C}$ by an electric element, while the upper section is insulated. The temperature of the bed is measured by a Pt-Pt10\%Rh thermocouple which can be moved along the axis of the bed. The gas distributor is a stainless steel plate with 53 holes ( $1 \mathrm{~mm}$ diameter) in an equilateral triangular pitch of $6.5 . \mathrm{mm}$. Its free cross section is $2.1 \%$. With this gas distribution device, the fluidisation is relatively uniform, reducing attrition due to gas jet effects [14]. A pre-heater raises the air temperature up to $550{ }^{\circ} \mathrm{C}$. The process conditions are listed in Table 3. 
TABLE 3. Particle properties and process conditions during the thermal shock, coal combustion and fluidisation experiments in the $0.05 \mathrm{~m}$ ID fluidised bed

Reactor pressure $(\mathrm{kPa})$

100

Superficial gas velocity $\left(\mathrm{m} \mathrm{s}^{-1}\right)$

2.0

Initial particle diameter sorbent $(\mathrm{mm})$

lime

$1.7-2.0$

synthetic

Particle diameter sand (mm)

Density sand (skeletal) $\left(\mathrm{kg} \mathrm{m}^{-3}\right)$

Fluidisation behaviour

Bed mixture: consisting of $150 \mathrm{~g}$ SG105

and $150 \mathrm{~g}$ sand

Measured minimum fluidisation velocity

ambient $\left(\mathrm{m} \mathrm{s}^{-1}\right)$

at $850{ }^{\circ} \mathrm{C}\left(\mathrm{m} \mathrm{s}^{-1}\right)$

Measured bed height at minimum fluidisation

ambient (m)

at $850^{\circ} \mathrm{C}(\mathrm{m})$

Average bed height

ambient (m)

at $850^{\circ} \mathrm{C}(\mathrm{m})$

$2.8-3.4$

$0.85-1.41$

3520

slugging

0.7

1.3

0.12

0.15

0.49

0.31

After each experiment, the sorbent, ash and sand were removed from the reactor by means of a vacuum system. A tube was lowered into the bed from the top, thus pneumatically conveying the bed material out into a container. The particles were then analysed by sieving (with USA ASTM E11-70 specified sieves). Tests showed that the emptying of the bed and the sieve analysis afterwards cause attrition as well. The reported sorbent losses were corrected for this effect by doing blank tests which will be described later.

\section{Thermal shock}

In this attrition experiment, about $300 \mathrm{~g}$ sand (representing bottom coal ash) is fluidised at $850^{\circ} \mathrm{C}$. A total amount of $75 \mathrm{~g}$ sorbent particles at room temperature is injected in portions of $10 \mathrm{~g}$ each, every 2 min (this procedure prevents a significant temperature decrease of the reactor bed). After all the sorbent is added, the heating is switched off. The bed is cooled down in $3.5 \mathrm{~h}$ while still being fluidised, to prevent thermal stress in the quartz reactor tube. The bed is then removed from the reactor and analysed by sieving.

The same procedure is applied for the blank test except that the sorbent is added while fluidising at ambient conditions followed by a relatively slow heating of the mixture to $850^{\circ} \mathrm{C}$ in approximately $1 \mathrm{~h}$.

The mass-based particle size distributions are determined after the experiments. Sorbent with a particle diameter below $1.4 \mathrm{~mm}$ is considered as attrition waste. Although the sulphur capture capability of these small particles is quite high, a sorbent-bottom ash separation would become difficult in a commercial sustem with culated diameter at which a sorbent particle is elutriated by the rising stream of gas at reactor conditions is approximately $0.4 \mathrm{~mm}$ for both lime and SG105 and thus much smaller than the threshold value of $1.4 \mathrm{~mm}$. Elutriated sorbent is thus not considered as a practical measurement problem.

Figure 3 presents the mass-based particle size distribution after the thermal shock experiment with (a) lime and (b) SG105. The small fraction (generally less than $5 \mathrm{wt} . \%$ ) of the sorbent above the largest particle size introduced is likely to originate from the sieving procedure rather than agglomeration. The latter was carefully inspected and not observed. The similarity between the blank and the non-blank experiments indicates that thermal shock has a negligible effect on the attrition of both lime and SG105 at the experimental conditions applied. The results are summarized in Table 4.

\section{Coal combustion}

In the coal combustion attrition experiments another production run of the synthetic sorbent was used, SG110 (Table 1), for practical reasons, with essentially the same properties as SG105. Here, a mixture of $150 \mathrm{~g}$ sand and $150 \mathrm{~g}$ sorbent is fluidised at $850{ }^{\circ} \mathrm{C}$. It is visually observed that no segregation occurs; the fluidised bed seems to be well-mixed during all the experiments. Then, $500 \mathrm{~g}$ coal (Thurston Property mine, USA), with a particle diameter between 1.4 and $2 \mathrm{~mm}$, is fed over the top of the reactor in portions of $5 \mathrm{~g}$ every $2 \mathrm{~min}$. The coal is burnt down in slightly less than $2 \mathrm{~min}$, thus the average coal content in the reactor is about $1 \mathrm{wt} . \%$, which matches the typical coal content of an industrial fluidised bed combustor. The coal used is specified in detail elsewhere [6]. The temperature of the bed is kept at approximately $850{ }^{\circ} \mathrm{C}$ and the reactor is allowed to operate for $3.3 \mathrm{~h}$. Then, the heating is switched off and the bed is cooled down in $3.5 \mathrm{~h}$. A blank test is performed by repeating the procedure without inserting the coal.

Figure 4 presents the mass-based particle size distribution of (a) lime and (b) synthetic sorbent after each experiment. It can be concluded that attrition of 1.7-2.0 mm particles of lime in a fluidised bed in the presence of coal combustion is not more than that in the absence of coal combustion as shown by the blank test. The resistance to attrition of SG110 sorbent under these conditions is significantly worse than in the blank test. A net mass fraction reduction of the initial sorbent diameter $(2.8-3.4 \mathrm{~mm})$ of $23 \mathrm{wt} \%$ is obtained (Table 4). The net amount of SG110 sorbent reduced in size 

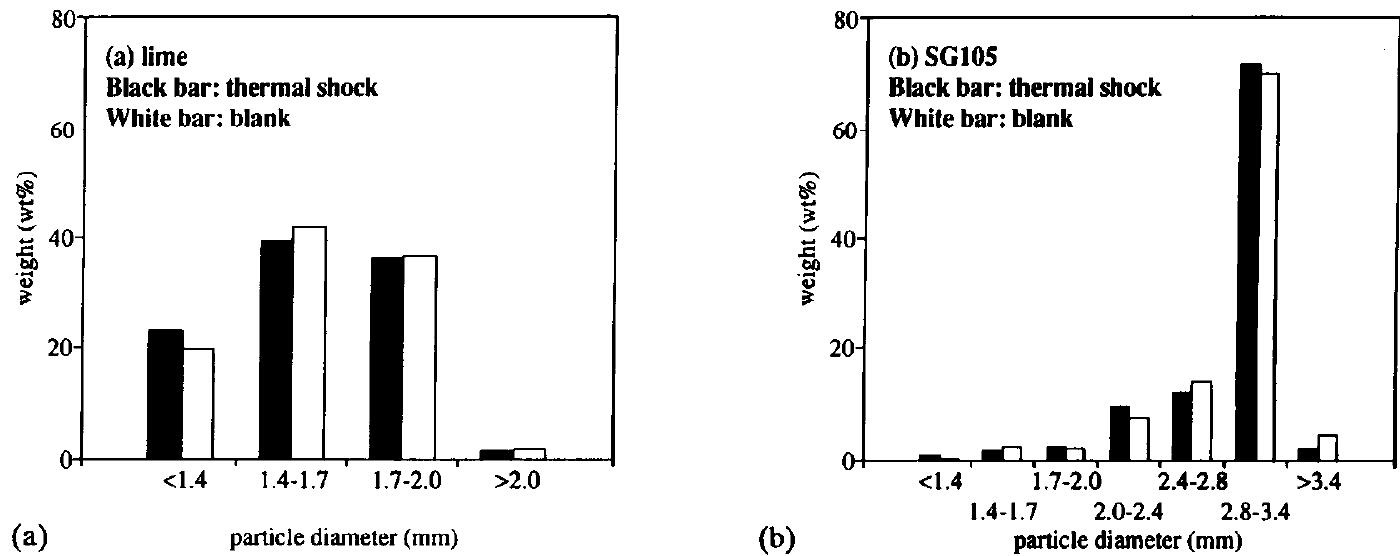

Fig. 3. Mass-based particle size distribution after a thermal shock experiment with (a) lime and (b) SG105 sorbent.

TABLE 4. Summary of attrition data of the sorbent after the thermal shock, coal combustion and fluidisation experiments

\begin{tabular}{|c|c|c|c|c|}
\hline Experiment & $\begin{array}{l}\text { Temperature } \\
\left({ }^{\circ} \mathrm{C}\right)\end{array}$ & $\begin{array}{l}\text { Experiment } \\
\text { time } \\
\text { (h) }\end{array}$ & $\begin{array}{l}\text { Reduction } \\
\text { initial size } \\
\text { (wt.\%) }\end{array}$ & $\begin{array}{l}\text { Mass fraction } \\
\text { above } 1.4 \mathrm{~mm} \\
\text { (wt.\%) }\end{array}$ \\
\hline \multicolumn{5}{|l|}{ Thermal shock } \\
\hline lime & (blank) & 0.25 & 62 & 80 \\
\hline lime & ambient -850 & 0.25 & 62 & 77 \\
\hline SG105 & (blank) & 0.25 & 26 & 100 \\
\hline SG105 & ambient-850 & 0.25 & 27 & 99 \\
\hline \multicolumn{5}{|l|}{ Coal combustion } \\
\hline lime & (blank) & 3.3 & 65 & 72 \\
\hline lime & 850 & 3.3 & 65 & 78 \\
\hline SG110 & (blank) & 3.3 & 42 & 97 \\
\hline SG110 & 850 & 3.3 & 65 & 95 \\
\hline \multicolumn{5}{|l|}{ Fluidisation } \\
\hline lime (blank) & ambient & - & 20 & 97 \\
\hline lime & ambient & 164 & 100 & 0 \\
\hline lime & 850 & 191 & 92 & 27 \\
\hline SG105 (blank) & ambient & - & 25 & 98 \\
\hline SG105 & ambient & 250 & 69 & 88 \\
\hline SG105 & 850 & 211 & 55 & 90 \\
\hline SG110 (blank) & ambient & - & 27 & 97 \\
\hline SG110 & ambient & 204 & 68 & 89 \\
\hline SG110 & ambient & 1220 & 79 & 83 \\
\hline SG110 & 850 & 233 & 65 & 88 \\
\hline
\end{tabular}

\section{Attrition by fluidisation}

During the fluidisation process, attrition occurs by interaction of the sorbent particles with each other, with the bed material and with the rest of the reactor system. To study the effect of kinetic stress, experiments were done with a mixture of $150 \mathrm{~g}$ sand and $150 \mathrm{~g}$ sorbent both at ambient conditions and at $850^{\circ} \mathrm{C}$. Also during this experiment no segregation occurs and the bed seems to be well-mixed during all experiments. Most experiments lasted on the order of $200 \mathrm{~h}$, and one as much as $1200 \mathrm{~h}$.
The mass-based particle size distribution is measured by sieving off-line several times during the experiment by emptying the bed and carrying out a sieve analysis of the bed inventory. All the particles are then put back into the bed and the attrition experiment is continued. A blank test is performed by repeatedly introducing equal times the bed material into the reactor, removing and sieving the solids at ambient conditions. Figure 5 shows a typical mass-based particle size distribution of (a) lime and (b) synthetic sorbent after $\sim 200 \mathrm{~h}$ fluidisation at $850{ }^{\circ} \mathrm{C}$. The synthetic sorbent shows considerably less attrition than lime. At ambient 


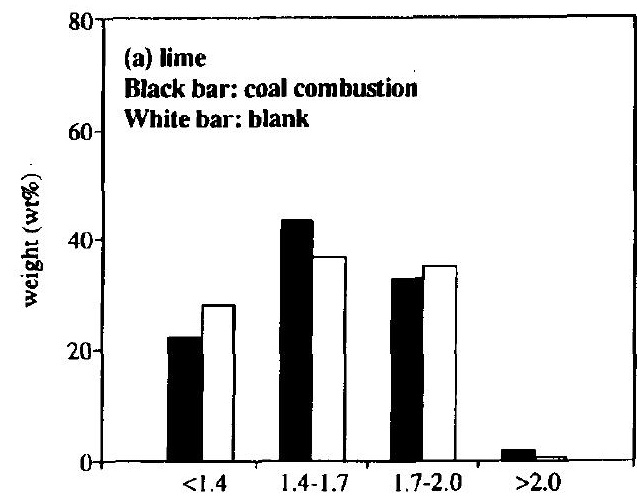

(a) particle diameter $(\mathrm{mm})$

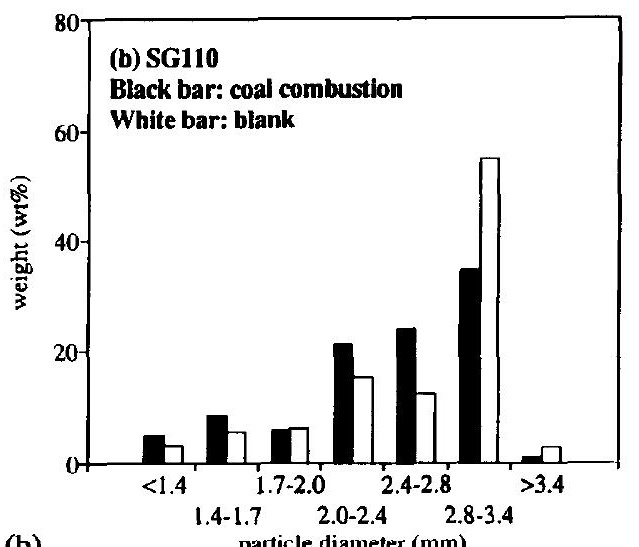

(b)

Fig. 4. Mass-based particle size distribution after a coal combustion experiment with (a) lime and (b) SG110 sorbent.

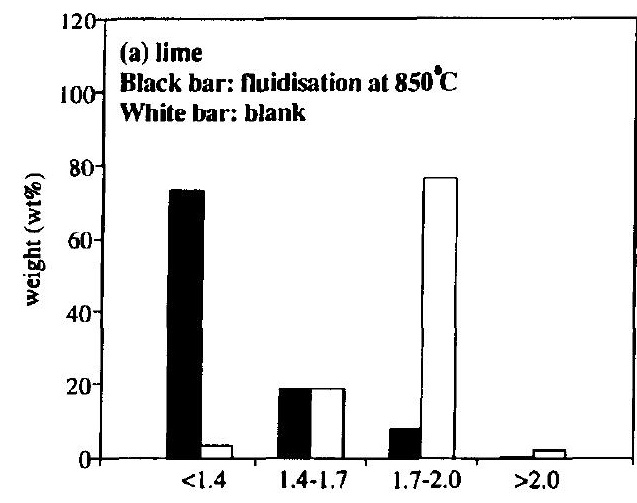

(a)

particle diameter $(\mathrm{mm})$

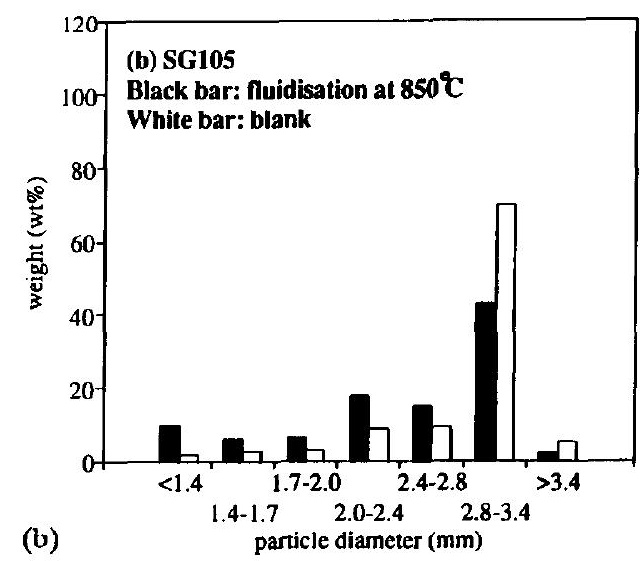

Fig. 5. Mass-based particle size distribution after $\sim 200 \mathrm{~h}$ fluidisation at $850{ }^{\circ} \mathrm{C}$ with (a) lime and (b) SG105 sorbent.

conditions the difference is even bigger, as then all lime is pulverised to below $1.4 \mathrm{~mm}$, while the attrition of the synthetic sorbent resembles that of Fig. 5(b). A review of the attrition data is given in Table 4.

As stated before, we have used $1.4 \mathrm{~mm}$ as a threshold for sorbent particles that can be employed in the intended regenerative sulphur capture process. Figure 6 illustrates the remaining mass (corrected with the blank test) above this level as a function of time during a fluidisation experiment for (a) lime and SG105 and (b) SG110. This is a decaying function for which several explanations may be given (see e.g. refs. 13, 15-18). A simple approach attributes the decay to a first order process proportional to the number of particles, so that:

$\frac{W}{W_{0}}=e^{-t / \tau}$

or to a second order process proportional to the square of the number of particles:
$\frac{W}{W_{0}}=\frac{1}{1+\frac{t}{\tau}}$

Equation (3) can be seen as a lumped description of processes, whereby the particles lose mass through interactions with the wall of the bed and the sand. These are assumed first order in the particle concentration. The second order process could be due to interactions between the initial, unfragmentated sorbent particles. In both cases the process is characterized by a single parameter, the time constant $\tau$. In the latter case, an estimate of this short time constant can be made by analogy to molecular collisions described by the molecular gas theory (e.g. [19]):

$$
\tau=\frac{1}{3600 C S v p}
$$

For a mixture of $150 \mathrm{~g} \mathrm{SG} 105$ and $150 \mathrm{~g}$ sand at the process conditions listed in Table $3\left(\right.$ at $850{ }^{\circ} \mathrm{C}$ ), the initial concentration of the sorbent particles $C$ is $10^{7}$ per $\mathrm{m}^{3}$. The initial particle outer surface area $S$ is 3 

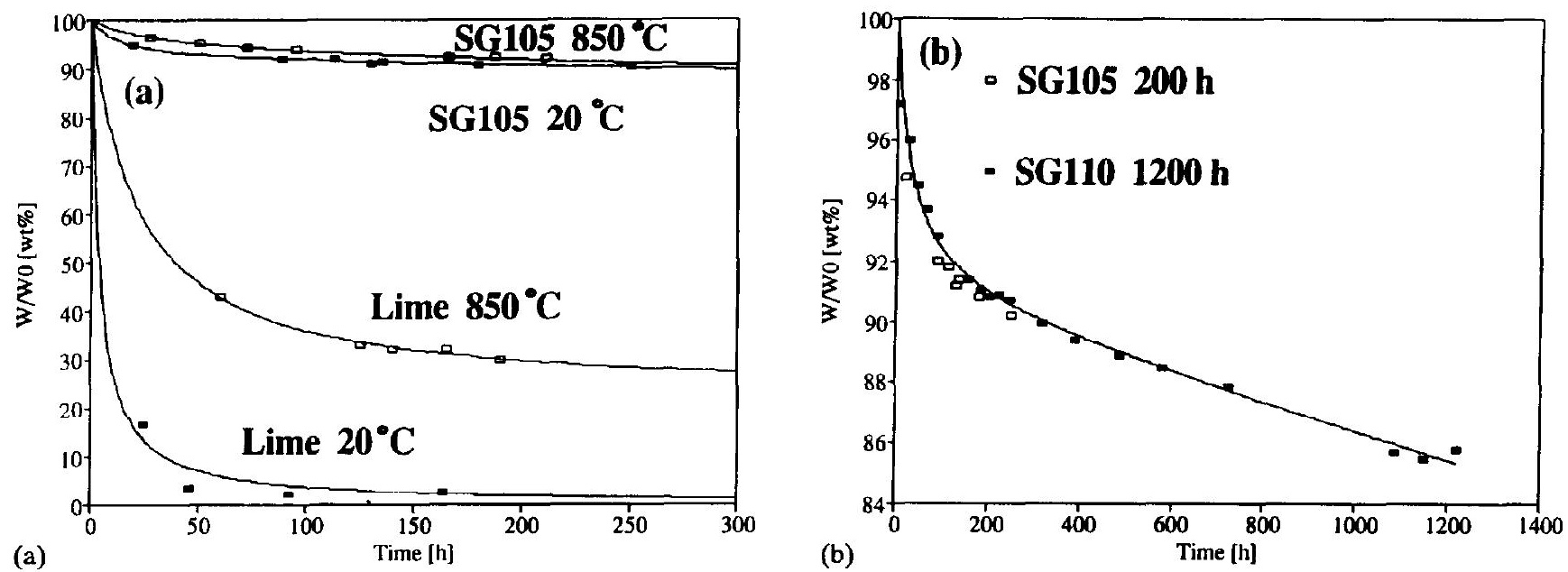

Fig. 6. Relative sorbent mass (diameter above $1.4 \mathrm{~mm}$ ) during fluidisation of (a) lime and SG105 sorbent at both ambient conditions and $850^{\circ} \mathrm{C}$ and (b) a long run SG110 sorbent at ambient conditions. The lines represent the fitted eqn. (6).

TABLE 5. Least-squares fit results of the attrition data by eqn. (6)

\begin{tabular}{|c|c|c|c|c|c|}
\hline Sorbent & $\begin{array}{l}\text { Temperature } \\
\left({ }^{\circ} \mathrm{C}\right)\end{array}$ & $\stackrel{f_{s}}{(-)}$ & $\begin{array}{l}\tau_{\mathrm{s}} \\
(\mathrm{b})\end{array}$ & $\begin{array}{l}\tau_{\mathrm{I}} \\
\text { (h) }\end{array}$ & $\begin{array}{l}\text { Standard } \\
\text { deviation } \\
(\%)\end{array}$ \\
\hline Lime & ambient & 1 & $3.83 \pm 0.81$ & - & 3.8 \\
\hline Lime & 850 & $0.780 \pm 0.011$ & $21.8 \pm 1.9$ & - & 5.9 \\
\hline SG105 & ambient & $0.0833 \pm 0.0033$ & $12.3 \pm 1.6$ & $12.0 \pm 2.310^{3}$ & 0.14 \\
\hline SG105 & 850 & $0.075 \pm 0.011$ & $35 \pm 10$ & $>610^{3}$ & 0.15 \\
\hline SG110 & ambient & $0.0924 \pm 0.0035$ & $29.7 \pm 4.4$ & $19.0 \pm 1.610^{3}$ & 0.38 \\
\hline SG110 & 850 & $0.101 \pm 0.029$ & $27 \pm 17$ & $>310^{3}$ & 0.52 \\
\hline
\end{tabular}

$10^{-5} \mathrm{~m}^{2}$. The particle (impact) velocity $v$ is assumed equal to the difference between the gas velocity and the minimum fluidisation velocity, thus $2-1.3=0.7 \mathrm{~m}$ $\mathrm{s}^{-1}$. The probability of breakage (Fig. 2 at $v=0.7 \mathrm{~m}$ $\mathrm{s}^{-1}$ ) $p$ equals $410^{-7}$. Equation (5) then estimates the time constant to be on the order of hours. The short term time constant observed in the experiments is indeed several hours (see below).

All possible combinations of eqns. (3) and (4) were tried on data taken with lime, SG105 and SG110. Bartlett's Chi-square test for model discrimination showed consistently that a curve described by eqn. (3) or (4) alone should be rejected. A short time constant component, 4 to $40 \mathrm{~h}$, and a long time constant component, $\sim 10^{4} \mathrm{~h}$, always appears. If all measurements were combined in one meta-analysis, the only choice for the short term component was eqn. (3), while the equivalent of both formulas fits if used for the long term component. We decided to apply:

$\frac{W}{W_{0}}=\frac{f_{\mathrm{s}}}{1+\frac{t}{\tau_{\mathrm{s}}}}+\left(1-f_{\mathrm{s}}\right) e^{-t / \tau_{1}}$ as a phenomenological description of the attrition curves because it is consistent with the data, and we accept the assumption that the long term attrition is mainly due to the first order process. Equation (6) is quite similar to that of Pis et al. [20] and Fuertes et al. [21]. The mass fraction $f_{\mathrm{s}}$ is of the initial sorbent subject to the short term attrition process. It is interesting to note that for the synthetic sorbent its value appears almost equal at both temperatures considered.

Table 5 summarizes the parameters obtained with eqn. (6) as applied to data from lime, SG105 and SG110, and Fig. 6 further shows the fit to the data which is corrected for the blank tests. From the analysis above (around eqns. (3) and (4)), the origin of the short term component in eqn. (6) is the collisions between the unfragmented particles until all weaker particles are broken at the prevalent particle velocities. The observed mass-based particle size distributions support this point of view because after some tens of hours the reduction of the initial fraction has reached a constant value. The long term component appears, from inspection of the mass-based particle size distributions, to be the slow decrease in diameter of the fragmented pieces. 
Based upon the final attrition rate of SG105 at 850 ${ }^{\circ} \mathrm{C}$, approximately 200 cycles (at a rather arbitrarily sorbent residence time of $50 \mathrm{~h}$ ) seem to be possible with respect to attrition by fluidisation.

\section{Conclusions and discussion}

The primary purpose of this study was to investigate

phurisation of flue gas in fluidised coal combustion. It has been found that the attrition resistance properties of the synthetic sorbent are orders of magnitude better than that of lime, when considering crushing strength, thermal shock and fluidisation experiments. It should be emphasized that for the fluid bed experiments the initial diameter of the lime(stone) particles is smaller than the initial diameter of the synthetic sorbent (Table 1 ), such that the results, as in the summary of Table 4 , are favouring the sorbent. It is because of its limited crushing strength that the lime(stone) particles cannot easily be retained at larger diameters, so that the general conclusion remains valid.

In the presence of coal combustion, the sorbent shows a lower attrition resistance in comparison to lime(stone). The exact cause of this effect cannot be traced here. It is recommended that in future studies of this type of sorbent special attention be paid to the effect of coal combustion on the mechanical stability of the sorbent.

From the point of view of attrition in the application of this sorbent to a possible future process, it can be seen from the impact tests that the probability of breakup is significant for impact velocities above $2 \mathrm{~m} \mathrm{~s}^{-1}$. This has consequences in particular for the design of the pneumatic conveying system. Claims are made in the literature for systems that achieve velocities as low as one or two metres per second [22].

The number of cycles that the sorbent can be usefully employed is determined by the long term attrition rate of the sorbent which is mainly determined by the resistance of the particles to slow abrasion. An estimate is that the sorbent SG105 can be applied for approximately 200 sulphation-regeneration cycles of $50 \mathrm{~h}$ per cycle based upon the attrition rate due to fluidisation only (thus without coal combustion). Then, the sorbent diameter is diminished to $1.4 \mathrm{~mm}$, below which the sorbent is considered as attrition waste. The attrition properties limit the life cycle of the sorbent, as the morphology changes are relatively small. The morphology of the sorbents was determined both before and after the thermal shock, coal combustion and fluidisation experiments performed at $850{ }^{\circ} \mathrm{C}$ (Table 6).
TABLE 6. Texture of the sorbent before (initial) and after the thermal shock, coal combustion and fluidisation experiments

\begin{tabular}{|c|c|c|c|c|c|}
\hline \multirow[t]{2}{*}{ Experiment } & \multirow[t]{2}{*}{$\begin{array}{l}\text { Temperature } \\
\left({ }^{\circ} \mathrm{C}\right)\end{array}$} & \multicolumn{2}{|c|}{$\begin{array}{l}\text { Surface area } \\
\left(\mathrm{m}^{2} \mathrm{~g}^{-1}\right)\end{array}$} & \multicolumn{2}{|c|}{$\begin{array}{l}\text { Pore volume } \\
\left(\mathrm{ml} \mathrm{g}^{-1}\right)\end{array}$} \\
\hline & & $N_{2}$ & $H g$ & $\mathrm{~N}_{2}$ & $\mathrm{Hg}$ \\
\hline \multicolumn{6}{|l|}{ Initial } \\
\hline lime & ambient & 5 & 3 & 0.02 & 0.31 \\
\hline SG105 & ambient & 99 & 80 & 0.29 & 0.22 \\
\hline $\operatorname{sa110}$ & ambient & 67 & 71 & א20 & חבת \\
\hline \multicolumn{6}{|l|}{ IInie } \\
\hline SG105 & 850 & 98 & 87 & 0.29 & 0.22 \\
\hline \multicolumn{6}{|c|}{ After coal combustion } \\
\hline lime & 850 & 6 & 3 & 0.02 & 0.26 \\
\hline SG110 & 850 & 77 & 77 & 0.24 & 0.22 \\
\hline \multicolumn{6}{|c|}{ After fluidisation } \\
\hline lime & 850 & 5 & 2 & 0.04 & 0.27 \\
\hline SG105 & 850 & 102 & 84 & 0.31 & 0.23 \\
\hline
\end{tabular}

In this work an attempt was also made to explain the observed single- and multi-particle fluidised bed tests. A tenuous link was observed between the scatter in crushing strength and breakage probability in shooting experiments. The description of the attrition process during fluidisation in eqn. (6) is simple and adequate, despite the complex phenomena behind it. It is intercsting to note that the short term attrition rate depends on the temperature, while the long term attrition rate of the synthetic sorbent appears to be unaffected by temperature. But it should be noted that the difference in temperature also means a difference in minimum fluidisation velocity and therefore a difference in attrition rate, because this is often claimed to be proportional to the difference between fluidisation and minimum fluidisation velocity (e.g. [18]).

\section{Acknowledgements}

The authors thank A. Fransen, L. den Hollander and $\mathrm{R}$. Versteeg for their contributions in the experimental work. We are grateful to M. Ghadiri, J.C. Schouten, C.M. van den Bleek and P.M.M. Vervoorn for their helpful suggestions. The financial support was obtained from the Commission of the European Communities (no EN3F-0014-NL(GDF)), the Netherlands Agency for Energy and Environment (No. 20.35-01630), the Netherlands Technology Foundation (No. DST77.1386), and Shell Internationale Petroleum Maatschappij B.V.

\section{List of symbols}

C concentration of sorbent particles, $1 / \mathrm{m}_{\text {bed }}^{3}$ 


\begin{tabular}{|c|c|}
\hline$F_{\mathrm{t}}$ & $\begin{array}{l}\text { sorbent particle break-up threshold force, } \\
\mathrm{N}\end{array}$ \\
\hline$f_{\mathrm{s}}$ & $\begin{array}{l}\text { mass fraction of weak sorbent material, } \mathrm{kg} / \\
\mathrm{kg}\end{array}$ \\
\hline$m$ & sorbent particle mass, $\mathrm{kg}$ \\
\hline$p$ & probability of breakage, - \\
\hline$S$ & sorbent particle outer surface area, $\mathrm{m}^{2}$ \\
\hline$t$ & time, $\mathrm{h}$ \\
\hline$v$ & sorbent particle (impact) velocity, $\mathrm{m} \mathrm{s}^{-1}$ \\
\hline$v_{\mathrm{t}}$ & $\begin{array}{l}\text { sorbent particle impact velocity at break- } \\
\text { up, } \mathrm{m} \mathrm{s}^{-1}\end{array}$ \\
\hline$W$ & mass of the sorbent, $\mathrm{kg}$ \\
\hline$W_{0}$ & initial mass of the sorbent, $\mathrm{kg}$ \\
\hline \multicolumn{2}{|c|}{ Greek letters } \\
\hline$\sigma$ & (sample) standard deviation, - \\
\hline$\tau$ & attrition rate time constant, $h$ \\
\hline$\tau_{\mathrm{I}}$ & long term attrition rate time constant, $h$ \\
\hline $\begin{array}{l}\tau_{\mathrm{s}} \\
\ln \sigma_{\mathrm{Ft}}\end{array}$ & $\begin{array}{l}\text { short term attrition rate time constant, } h \\
\text { geometric standard deviation of the break- } \\
\text { up threshold force, - }\end{array}$ \\
\hline $\ln \sigma_{\mathrm{g}}$ & geometric standard deviation, - \\
\hline $\ln \sigma_{\mathrm{m}}$ & $\begin{array}{l}\text { geometric standard deviation of the particle } \\
\text { mass, - }\end{array}$ \\
\hline $\ln \sigma_{\mathrm{Vt}}$ & $\begin{array}{l}\text { geometric standard deviation of the impact } \\
\text { velocity at break-up, - }\end{array}$ \\
\hline
\end{tabular}

Abbreviations

ID internal diameter

SG105, synthetic sorbent prepared by the sol-gel SG110 method

\section{References}

1 E.H.P. Wolff, A.W. Gerritsen and C.M. van den Bleek, Proc. 10th Int. Conf. on Fluidized Bed Combustion, San Francisco, April 30--May 3, 1989, p. 603.

2 E.H.P. Wolff, A.G. Montfoort and C.M. van den Bleek, Desulphurisation 2, Technologies and Strategies for Reducing Sulphur Emissions, Hemispheres, London, UK, 1991, p. 175.

3 E.H.P. Wolff, A.W. Gerritsen and C.M. van den Bleek, Can. J. Chem. Eng., 71 (1993) 83.

4 A.E. Duisterwinkel, Ph.D. Thesis, Delft University of Technology, Delft, Netherlands, 1991.

5 A.E. Duisterwinkel, Katalysator - en sorbent bereiding, Dutch Pat. Application 90.01097 (May 8, 1990).

6 E.H.P. Wolff, Ph.D. Thesis, Delft University of Technology, Delft, Netherlands, 1991.

7 C.M. van den Bleek, E.B.M. Doesburg, A.E. Duisterwinkel, G. Frens, A.W. Gerritsen, G. Hakvoort, R. Korbee, W.G. Lin, J.C. Schouten, P.J.M. Valkenburg, P.J.T. Verheijen and E.H.P. Wolff, Regenerative Desulphurisation in Fluidized Bed Combustion of Coal, CEC-reports, 1986-1992.

8 W.G. Vaux and D.L. Keairns, in J.R. Grace and J.M. Matsen (eds.), Fluidization, Proc. 1980 Int. Fluidization Conf., Plenum Press, New York, 1980, p. 437.

9 C.R. Bemrose and J. Bridgwater, Powder Technol, 49 (1987) 97.

10 American ASTM Standard D4179, Single Pellet Crush Strength of Formed Catalyst Shapes, American Society for Testing Materials, 1982 .
11 P.M.M. Vervoorn, M.C. Franken, J.K. Hoeksma and B. Scarlett, Pneumatech 2: Int. Conf. on Pneumatic Conveying Technology, London, UK, 1984, p. 315.

12 P.M.M. Vervoorn and L.G. Austin, Powder Technol., 63 (1990) 141.

13 M.A. Chraibi and G. Flamant, Powder Technol., 59 (1989) 97.

14 V.N. Blinichev, V.V. Strel'tsov and E.S. Lebedeva, Int. Chem. Eng., 8 (1968) 615.

15 T.P. Chen, C.I. Sishtla, D.V. Punwani and H. Arastoopour, in J.R. Grace and J.M. Matsen (eds.), Fluidization, Proc. 1980 Int. Fluidization Conf., Plenum Press, New York, 1980, p. 445.

16 K. Patel, A.W. Nienow and I.P. Milne, Powder Technol., 47 (1986) 257.

17 C. Sishtla, J. Findlay, I. Chan and T.M. Knowlton, Proc. Int. Conf. on Fluidization VI, Engineering Foundation, New York, USA, 1989, p. 581.

18 P. Ayazi Shamlou, Z. Liu and J.G. Yates, Chem. Eng. Sci., 45 (1990) 809.

19 C. Kittel and H. Kramer, Thermal Physics, Freeman, 1989, Ch. 14.

20 J.J. Pis, A.B. Fuertes, V. Artos, A. Suárez and F. Rubiera, Powder Technol., 66 (1991) 41.

21 A.B. Fuertes, J.J. Pis, J.C. García, F. Rubiera and V. Artos, Powder Technol., 67 (1991) 291.

22 British Materials Handling Board, Particle Attrition State-ofthe-Ant Review, Series on Bulk Materials Handling, Vol. 5, Trans Tech, Clausthal-Zellerfeld, Germany, 1987, Chs. 3 and 5.

\section{Appendix: the log-normal distribution}

The basic properties of the log-normal distribution are summarized here. The essential idea is that if $\ln \left(\left(X-x_{0}\right) / X_{\mathrm{g}}\right) / \ln \sigma_{\mathrm{g}}=N(0,1)$, the stochastic variable $X$ has a log-normal distribution. Often if $x_{0}=0$, then the subsequent formula for the distribution $f(x)$ of $X$ is

$f(x)=\frac{1}{\sqrt{2 \pi} \ln \sigma_{\mathrm{g}}} \exp \left[-\frac{\ln ^{2}\left(\frac{x}{x_{\mathrm{g}}}\right)}{2 \ln ^{2} \sigma_{\mathrm{g}}}\right] \frac{1}{x}$

$x_{\mathrm{g}}=\frac{x_{\mathrm{avc}}}{\sqrt{1+\frac{\sigma^{2}}{x_{\mathrm{ave}}^{2}}}}$

$\ln \sigma_{\mathrm{g}}=\sqrt{\ln \left(1+\frac{\sigma^{2}}{x_{\mathrm{ave}}^{2}}\right)}$

Average: $x_{\text {ave }}=x_{\mathrm{g}} \exp \left[\left(\ln ^{2} \sigma_{\mathrm{g}}\right) / 2\right]$

Standard deviation:

$\sigma=x_{\mathrm{g}} \exp \left[\left(\ln ^{2} \sigma_{\mathrm{g}}\right) / 2\right]\left(\exp \left[\ln ^{2} \sigma_{\mathrm{g}}\right]-1\right)^{0.5}$

The parameter ' $\ln \sigma_{\mathrm{g}}$ ' is the geometric standard deviation, a dimensionless number. It is always quoted as such, while seldom is the exponent taken. In the mathematical literature the parameter ' $\ln \sigma_{\mathrm{g}}$ ' is therefore not uncommonly replaced by ' $\sigma_{\mathrm{g}}$ ' alone. We will continue to use ' $\ln \sigma_{g}$ ', because the particle technology literature persists in this notation. 